\title{
Anomalous Behavior of a Solid Rocket Motor Nozzle Insert During Static Firing Test
}

\author{
Ronald Izidoro Reis ${ }^{1}$, Wilson Kiyoshi Shimote², Luiz Claudio Pardini
}

\begin{abstract}
This paper presents the study and development of a firing test used to evaluate the behavior of a solid rocket motor. The motivation for the development of a subscale solid rocket motor with end burning propellant grain geometry arose from the need to evaluate the nozzle inserts of graphite for the possible replacement with the carbon fiber-reinforced carbon composite. These subscale solid rocket motors, simulating full scale motor operating time, but with mass flow far below, aim to determine the ablative characteristics of composite materials as a function of operating time. The objective was to correlate the mass flow between subscale solid rocket motors and full scale using insert data materials such as graphite and carbon fiber-reinforced carbon composites, which have ablative characteristics determined in subscale solid rocket motors used at the Instituto de Aeronáutica e Espaço. The critical section to evaluate the test device is rocket nozzle throat region. Analysis of the materials of the subsonic and supersonic nozzle insert parts was performed after the burning tests. It was found the formation of a thin layer of material deposited after the test. The deposited coating layer was analyzed by electron dispersive $x$-ray analysis and scanning electron microscopy. The results analyzed by these methods showed that there were aluminum and carbon in the coating. Finally, the material was analyzed by x-ray diffraction, and the results showed the presence of aluminum oxide. It was also noticed that, because of the unexpected coating deposition forming material in exit conical and throat of the insert that the effect of ablation was not observed.
\end{abstract}

KEYWORDS: Propulsion, Subscale motor, Nozzle inserts, Graphite, Firing test.

\section{INTRODUCTION}

Subscales of solid rocket motors (SRM) are devices used for propellant development and for propellant ballistic parameters control. These subscale motor provide an estimation of fullscale motor performance at as small as possible motor size. Because of this, a reduced amount of propellant is needed, and reliable results related to the burning test can be achieved. Also, subscale motors are a classroom lesson for understanding the performance of solid rockets, since in general the delivered specific impulse is the main target (Geisler and Beckman 1998). The subscale SRM is also a useful tool to study problems related to the effect of multiple chamber lengths, submergence nozzle, end burners, nozzle inserts, insulation capability and ablation rate (Wermimont 1993; Cortopassi et al. 2009; Delaney et al. 1964). Thus, subscale rocket motors are those in a lab scale and a benchmark for real-size rocket launchers. Najjar et al. (2005) used a similar model of a SRM in their study.

Since the late 1960s, when the Instituto de Aeronáutica e Espaço (IAE) started the development of SRM for the Brazilian Space Program, subscale rocket motors have been used to perform testimony tests aiming the quality control of burning rate parameters and energetic characteristics for solid propellants. The burning rate determination method consists of burning a set of motors under different chamber pressures, which is accomplished basically by using different nozzle throat diameters.

Another important evaluation that can be done, besides burning time and ablation, which are related to the small amount of propellant burning characteristics, is the evaluation of the thermal protection materials, the behavior of the thermal protection materials and nozzle insert material. The thermal

1.Departamento de Ciência e Tecnologia Aeroespacial - Instituto de Aeronáutica e Espaço - Divisão de Materiais - São José dos Campos/SP - Brazil. 2.Departamento de Ciência e Tecnologia Aeroespacial - Instituto de Aeronáutica e Espaço - Divisão de Propulsão Espacial - São José dos Campos/SP - Brazil.

Author for correspondence: Ronald Izidoro Reis | Departamento de Ciência e Tecnologia Aeroespacial - Instituto de Aeronáutica e Espaço - Divisão de Materiais | Praça Marechal Eduardo Gomes, 50 - Vila das Acácias | CEP: 12.228-015 - São José dos Campos/SP - Brazil | Email: izidororir@iae.cta.br

Received: 04/14/2016 | Accepted: 07/25/2016 
protections and the nozzle throat are adapted in order to test the material of the nozzle throat insert systems and allow definite burning times, from 10 up to $70 \mathrm{~s}$, using a propellant grain size having appropriate end-burning configuration. This paper presents an investigation of the ablation phenomena in the nozzle throat region during firing tests using graphite inserts. Analysis of the materials from the subsonic and supersonic nozzle insert parts was performed after the end of burning tests. It has been found the formation of a deposited thin layer of burned material after the test. The deposited coating layer was analyzed by electron dispersive $\mathrm{x}$-ray analysis (EDX) and scanning electron microscopy (SEM). The main changed components from the previous design of the SRM were the nozzle insert, steel tip and rear convergent thermal protection, as shown in Fig. 1, as well as the characteristics of propellant grain geometry, from start-burning to end-burning configuration, and the motor case thermal protection.

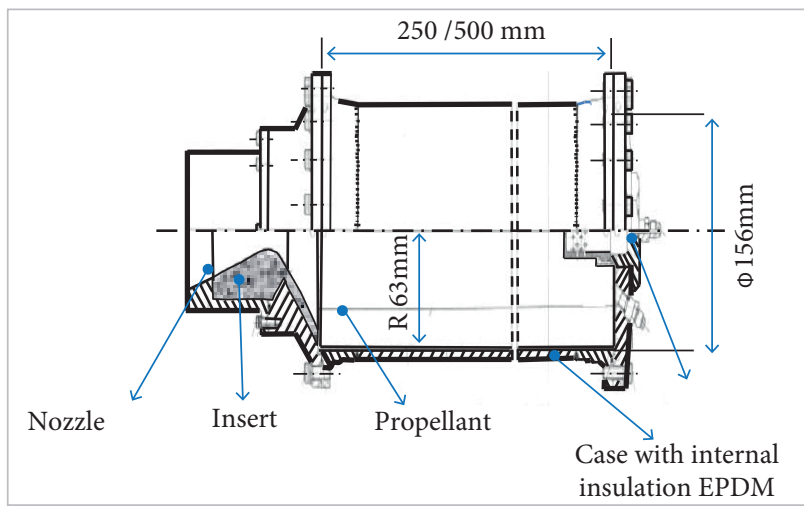

Figure 1. Subscale rocket motor used at IAE.

\section{MATERIALS AND METHODOLOGY}

A polycrystalline graphite HLM-85, from Sigri/SGL (Great Lakes Carbon Corporation), was used as a nozzle insert. Graphite and other carbon composites, such as carbon fiber-reinforced carbon composites, are materials that have a significant high emissivity $(>0.8)$. High emissivity is a performance requirement for rocket nozzle throats since they transfer and sink energy absorbed from the environment. Then, the metallic structure from the steel tip is isolated from high temperatures exerted from the propellant, during the lifetime of the firing test. Figure 2 shows a view of the rocket nozzle insert. The rocket nozzle exit used in the tests has a diameter of $18 \mathrm{~mm}$ and a critical diameter (smallest cross section) of $8 \mathrm{~mm}$.
The rocket nozzle is assembled in a steel tip, as shown in Fig. 3, by a bond line between the insert ablative composite material/ graphite and the rear cover of the convergent subscale motor (Fig. 4). An appropriate bond line has been well-designed to avoid damage to the nozzle system during firing.

The rocket nozzle insert and the steel tip were integrated and further assembled in the rear cover convergent, as shown in Fig. 5a. The assembled nozzle is presented in Fig. 5b. The rear cover system has as a main function to provide the gas flow direction and structurally withstands the internal pressure of gases generated by burning of the propellant.

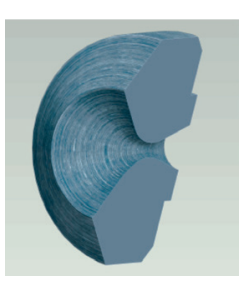

Figure 2. Cross section view and shape of a rocket nozzle insert of graphite.

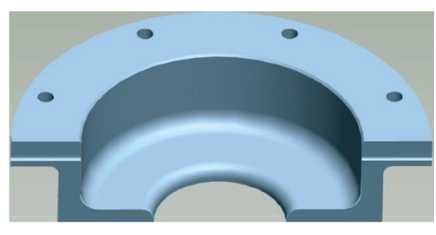

Figure 3. Steel tip from the nozzle system.

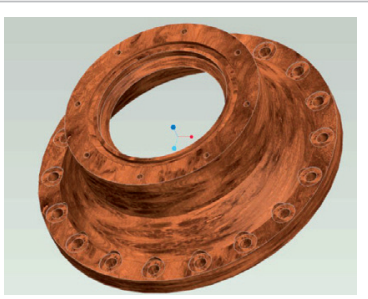

Figure 4. Rear cover convergent ablative material from the nozzle system.
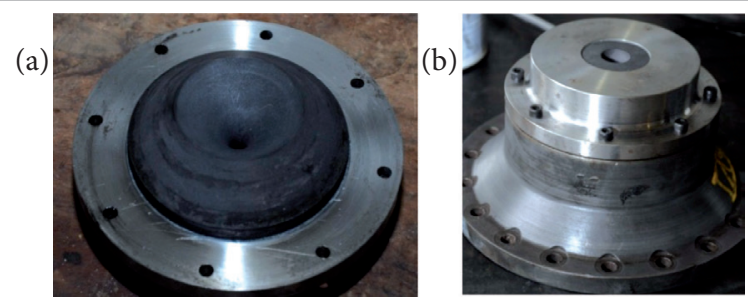

Figure 5. Rocket nozzle assembly. (a) Graphite nozzle insert; (b) Assembled nozzle. 
The nozzle/steel tip is assembled in a cylindrical motor case, the rocket envelop, as schematically shown in Fig. 6, by fitting the component parts integrated by the steel tip. Figure 7 shows the subscale solid rocket motors e integrated with the exit nozzle.

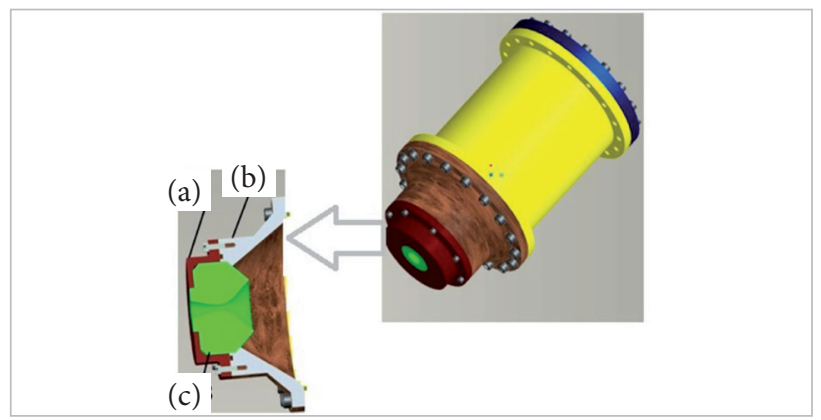

Figure 6. Subscale motor assembly. (a) Steel tip; (b) Rear convergent section; (c) Nozzle insert.

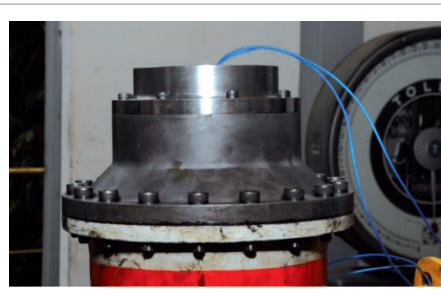

Figure 7. View of the rocket nozzle integrated to motor case.

During the burning test, the internal maximum chamber pressure in the motor case reaches a value of $9 \mathrm{MPa}$, and the thrust, a value of $250 \mathrm{~N}$. The ablation phenomenon is strongly dependent on the operation time, chamber pressure and propellant combustion gases (Thakre and Yang 2007). The end-burning propellant grain geometry produces constant pressure and thrust curves in the motor case, suitable to study the ablation phenomenon because increased burning times are achieved by using the star-burning configuration. From the experimental thrust curves, the motor operation time is obtained directly, from the burning test, and chamber pressure is calculated by using Eqs. 3 to 7 .

The solid composite propellants usually have a concentration of aluminum powder in the range of 1 to $15 \%$ by weight (Sciamareli et al. 2002). The propellant used in this study, during the static firing tests of the SRM, has $10 \%$ by weight of hydroxyl-terminated polybutadiene (HTPB) resin in liquid phase, $68 \%$ by weight of ammonium perchlorate $\left(\mathrm{NH}_{4} \mathrm{ClO}_{4}\right)$ in solid phase and $16 \%$ of high powder aluminum concentration. The increase in the amount of aluminum power added to the propellant formulation increases the gas temperature, the propellant density and the propellant performance (Sutton 1986; Kubota 2007).
The firing tests were carried out at burning times from 9 to $56 \mathrm{~s}$ by changing the propellant mass: $3.35 ; 4.67$ and $7.05 \mathrm{~kg}$. The thrust was measured by using a load cell fitting the front lid of the motor case. This arrangement allows the assessment of the behavior of ablation from both graphite nozzle insert and the thermal protections.

Measurements of the surface internal profiles of the nozzle insert and from the convergent section were done before and after the firing test by a coordinate measuring machine Zeis Accura. These measurements allow to estimate the insulation efficiency of the thermal protection of the convergent section and nozzle insert material during the motor static firing test. An anomalous increase in the area of the critical section (nozzle throat) is detrimental to the operation of the motor due to the reduction in the nozzle expansion ratio and the value of rocket motor specific impulse.

According to Wani et al. (2012), most composite propellants contain typically ammonium perchlorate at proportions ranging from 65 to $70 \%$ by weight, a metallic fuel like aluminum powder at proportions ranging from 15 to $20 \%$ by weight and a rubberlike binder, such as HTPB, at proportions ranging from 10 to $15 \%$ by weight. These 3 constituents can correspond approximately to the amount of $95 \%$ by weight of the propellant weight (Glotov 2006; Susuki and Chiba 1989). A similar propellant formulation has been applied in the rocket motors used in the Brazilian Space Program. Particularly, in this research, a propellant formulation based on a composition of ammonium perchlorate, aluminum powder and HTPB resin was also used according to Sciamareli et al. (2002).

After the firing tests, the analysis of the internal surface of nozzle inserts was carried out by EDS through an OXFORD equipment, model 7059, as well as software INCA and SEM, through LEO model 435VPi. X-ray diffraction was done in a PANalytical equipment, model XPert PRO, and the analysis conditions were: $\mathrm{CuK} \alpha$ radiation $(\lambda=1.54056 \mathrm{~A})$; voltage $40 \mathrm{kV}$ and $45 \mathrm{~mA}$ of current; the scan ranged from 5 to 90 , and the step was $0,016^{\circ} \cdot \mathrm{min}^{-1}$.

The subscale motor has end burning grain geometry. In this case, it is expected that the thrust curve remains constant throughout the firing test. The dependency of the critical section area on the rocket nozzle as a function of pressure and thrust values is given by Eqs. 1 to 8 . The nozzle thrust coefficient, $C_{F}$ (Eq. 3), is proportional to the chamber pressure and to the critical section area.

$$
I_{s p}=C^{*} \cdot C_{F}
$$


where: $I_{s p}$ is the solid rocket motor specific impulse $\left(\mathrm{m} \cdot \mathrm{s}^{-1}\right)$; $C^{*}$ represents propellant characteristic velocity $\left(\mathrm{m} \cdot \mathrm{s}^{-1}\right) ; C_{F}$ means nozzle thrust coefficient.

$C^{*}$ is given by Eq. 2 , and $C_{F}$, by Eq. 3 :

$$
C^{*}=\frac{\sqrt{R \cdot T_{O}}}{\sqrt{\gamma} \cdot\left(\frac{2}{\gamma+1}\right)^{\frac{(\gamma+1)}{2 \cdot(\gamma-1)}}}
$$

where: $R$ represents the gas constant $\left(312 \mathrm{~J} \cdot \mathrm{kg}^{-1} \cdot \mathrm{K}^{-1}\right) ; T_{o}$ is the adiabatic flame temperature $(\mathrm{K}) ; \gamma$ represents specific heat ratio of the burning gas.

$$
C_{F}=\sqrt{\left.\frac{2 \cdot \gamma^{2}}{\gamma-1} \cdot\left(\frac{2}{\gamma+1}\right)^{\frac{\gamma+1}{\gamma-1}} \cdot 1-\left(\frac{p_{e}}{p_{c}}\right)^{\frac{\gamma-1}{\gamma}}\right]}+\frac{A_{e}}{A_{c r}} \cdot\left(\frac{p_{e}}{p_{c}}-\frac{p_{a}}{p_{c}}\right)
$$

where: $p_{e}$ is the nozzle exit pressure $(\mathrm{Pa}) ; p_{c}$ is the combustion chamber pressure $(\mathrm{Pa}) ; p_{a}$ is the atmospheric pressure $(\mathrm{Pa}) ; A_{e}$ is the nozzle exit section area $\left(\mathrm{m}^{2}\right) ; A_{c r}$ is the nozzle critical section area $\left(\mathrm{m}^{2}\right)$.

The nozzle thrust coefficient $\left(C_{F}\right)$ is a function of gas specific heat $(\gamma)$, the nozzle area ratio $\left(A_{e} / A_{c r}\right)$, and the pressure ratio across the nozzle $\left(p_{e} / p_{c}\right)$. The propellant mass flow rate $\left(\mathrm{kg} \cdot \mathrm{s}^{-1}\right)$ is given by:

$$
\dot{m}=\frac{p_{c} \cdot A_{c r}}{C^{*}}
$$

The combustion chamber pressure is given by:

$$
p_{c}=\left(a \cdot C^{*} \cdot \rho_{p}\right)^{\frac{1}{1-n}} \cdot\left(\frac{S_{b}}{A_{c r}}\right)^{\frac{1}{1-n}}
$$

where: $S_{b}$ is the propellant burning surface area $\left(\mathrm{m}^{2}\right) ; \rho_{p}$ is the propellant density $\left(\mathrm{kg} \cdot \mathrm{m}^{-3}\right) ; a$ is an empirical constant influenced by propellant temperature and is known as burning rate coefficient variable, being dimensionless; $n$ is the burning rate pressure exponent (dimensionless).

According to Davenas (1993), the coefficient $a$ and the pressure exponent $n$ are given by the equation of Saint Robert and Vieille:

$$
\mathrm{V}_{\mathrm{b}}=\mathrm{a} \cdot \mathrm{P}_{\mathrm{c}}^{\mathrm{n}}
$$

where: $V_{b}$ is the solid propellant burning rate $\left(\mathrm{mm} \cdot \mathrm{s}^{-1}\right)$; $p_{c}$ is the combustion chamber pressure (MPa); $a$ and $n$ are obtained from the burning of subscale test motor at different chamber pressures.

The solid rocket motor thrust (in N) is given by:

$$
\begin{aligned}
& F=p_{c} \cdot A_{C r} \cdot C_{F} \\
& \quad \text { or } \\
& F=\dot{m} \cdot I_{s p}
\end{aligned}
$$

\section{RESULTS AND DISCUSSION}

Figure 8 shows a typical theoretical behavior of a solid rocket motor firing test where thrust and pressure are given as a function of time. The curve gives a theoretical idea of the influence of nozzle insert ablation on the pressure and thrust. Results show theoretical calculations from the chamber pressure as a function of the propellant burning rate characteristics. The graph of Fig. 8 was calculated by using Eqs. 5 and 7, defined by the coefficients $a=3.42 \mathrm{~mm} \cdot \mathrm{s}^{-1}$ and $n=0.25$ from Eq. 6 , the propellant characteristic velocity $\left(C^{*}=1,551 \mathrm{~m} / \mathrm{s}\right)$ was calculated from Eq. 2 where the adiabatic flame temperature $(T o=3,200 \mathrm{~K})$ and specific heat ratio $(\gamma=1.2)$; the nozzle thrust coefficient $\left(C_{F}=1.4\right)$ was calculated from Eq.3. In this equation atmospheric pressure $(\mathrm{Pa}=98.4 \mathrm{kPa})$, the nozzle exit pressure $\left(P_{e}=9.4 \times 104 \mathrm{~Pa}\right)$, nozzle exit section area $\left(A_{e}=2.54 \times 10^{-4} \mathrm{~m}^{2}\right)$ and the nozzle critical section area $\left(A_{c r}=5 \times 10^{-5} \mathrm{~m}^{2}\right)$. Finaly the combustion chamber pressure was calculated from Eq. 5 where propellant density $\left(\rho_{p}=1,700 \mathrm{~kg} \cdot \mathrm{m}^{-3}\right)$ and the propellant grain burning surface $\left(S_{b}=7.24 \times 10^{-3} \mathrm{~m}^{2}\right)$.

The values of thermodynamic properties, $T_{o}, \gamma$ and $R$, are obtained from CETPC 273 (1994) thermochemical equilibrium calculation software, which takes into consideration the propellant chemical composition, the reactants mass percentage, the reactants heat of formation, the expansion nozzle ratio and the operating stagnation pressure in the SRM combustion chamber (Zucrow and Hoffman 1976).

The coefficient $a$ and pressure exponent $n$ are given by Eq. 6, which shows the dependence of the solid propellant regression rate on the operating pressure, and were obtained by burning subscale SRM at different chamber pressures. With fine ammonium perchlorate $(3 \mu \mathrm{m})$, the pressure exponent $n$ is around $0.50-0.55$, while, for somewhat large perchlorate (10 $\mu \mathrm{m}), n$ may drop to as low as 0.45 (Davenas 1993). In this 
study, the ammonium perchlorate grain size is between 30 and $400 \mu \mathrm{m}$, then the pressure exponent is near 0,25 .

According to Davenas (1993), the range of composite solid propellant burning rate varies from 5 to $50 \mathrm{~mm} \cdot \mathrm{s}^{-1}$. Therefore, by knowing the value of $n$, it is possible to calculate the value of $a$ through Eq. 6 . In the present study, the propellant burning rate value is $5.35 \mathrm{~mm} \cdot \mathrm{s}^{-1}$ for operating pressure of 6.0 MPa.

For end-burning grain configuration, the burning surface $S_{b}$ is kept constant during the motor operation time. On the other hand, if the nozzle critical section increases, the chamber pressure and thrust decrease marginally, as shown in Fig. 8.

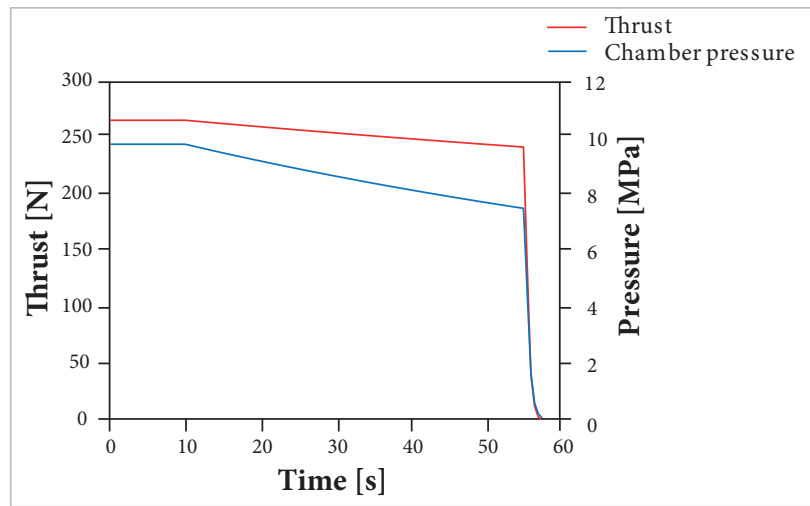

Figure 8. Theoretical behavior of a SRM showing the pressure and thrust as a function of time during a firing test.

The pressure chamber reduces significantly as the propellant is consumed.

In a real firing test, the critical diameter increases and the thrust coefficient reduces. Thus, the pressure in the rocket motor chamber and the propellant burning velocity reduce and the burning time increases. The thrust losses can be calculated in terms of $I_{s p}$, which is defined in Eq. 8.

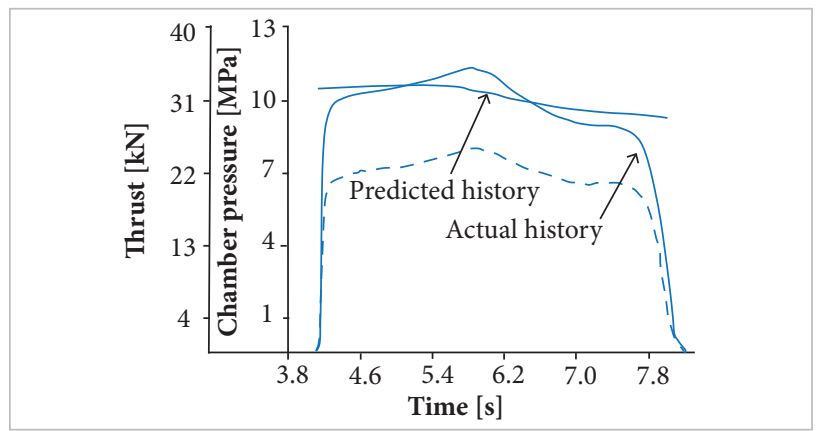

Figure 9. Profiles of pressure (continuous line) and thrust (dotted line) of a 70-pound motor as a function of time, during a firing test. Predicted behavior is also depicted. Source: Geisler and Beckman (1982).
Geisler and Beckman (1982) reported the behavior of a solid motor test firing, as shown in Fig. 9. A similar performance can be found when a comparison is made with the results presented in Fig. 8. Figure 9 shows that pressure and thrust reduce as the firing test goes to the end.

Figure 10 shows the results of thrust as a function of time history during static firing tests. All the tests showed a sharp increase in pressure chamber immediately after the beginning of the firing test. For the 9-s test (Fig. 10a), the thrust remains constant throughout the test, as a function of time at a thrust pressure near $325 \mathrm{~N}$. For the 37-s test (Fig. 10b), the thrust reduces just after reaching the peak at $350 \mathrm{~N}$, stabilizing the thrust at $250 \mathrm{~N}$. This behavior is similar to the one found in the test conducted for $55 \mathrm{~s}$ (Fig. 10c), where the thrust also reached a peak at $350 \mathrm{~N}$, stabilizing the thrust after $30 \mathrm{~s}$ of firing.

The results of these 3 firing tests were analyzed in this study to evaluate the ablation of EPDM rubber as a thermal protection

(a)

(b)

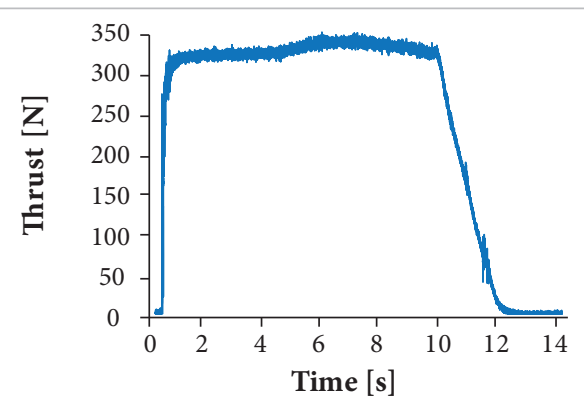

(c)
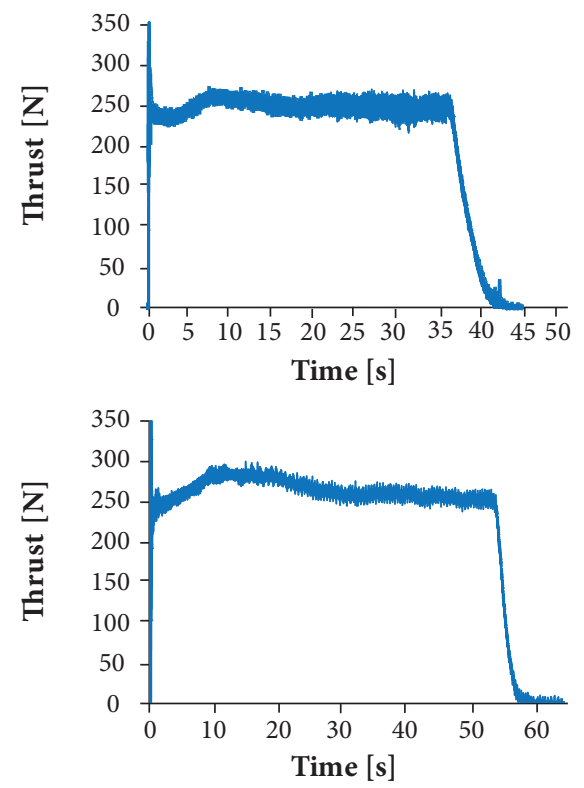

Figure 10. Experimental profile curves of the solid motor test showing the thrust at various throat diameters. (a) $9 \mathrm{~s}, 6 \mathrm{~mm}$ throat; (b) $37 \mathrm{~s}, 8 \mathrm{~mm}$ throat; (c) $55 \mathrm{~s}, 8 \mathrm{~mm}$ throat. 
from the convergent exit cone section of the nozzle. The initial tests were performed considering different burning times in order to compare the firing behavior. The operation time of the first firing test was $9 \mathrm{~s}$ (Fig. 11a), and the second one, $37 \mathrm{~s}$ (Fig. 11b). The last firing test was performed in $56 \mathrm{~s}$ (Fig. 11c).

In all firing tests, the formation of a dense coating deposit over the surface of the nozzle throat insert (convergent and divergent region) was observed. The condensed coating material was taken from the surface of the nozzle insert, as shown in Fig. 11, for analysis. Figure 12 shows close-up views of the extracted deposited coating at the nozzle entrance.
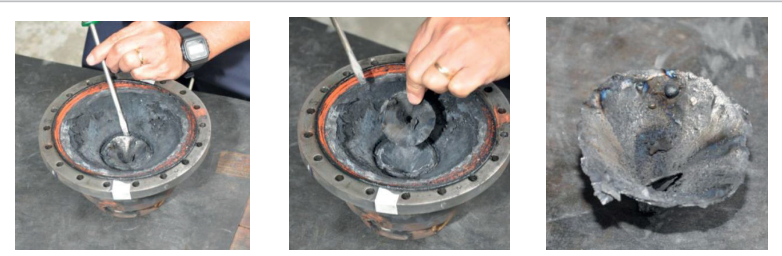

Figure 11. Removal of condensed material coating from the nozzle entrance after the firing test.
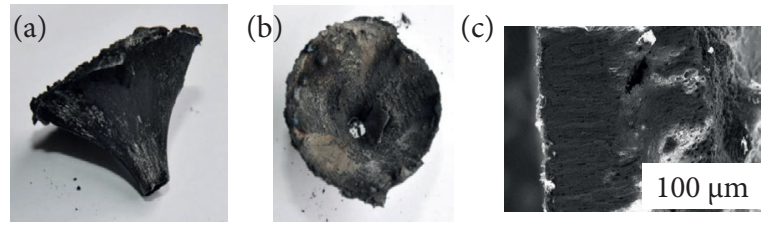

Figure 12. Images of the material deposited over the nozzle throat insert. (a) Side view; (b) Top view; (c) Cross section (38X magnification).

(a)

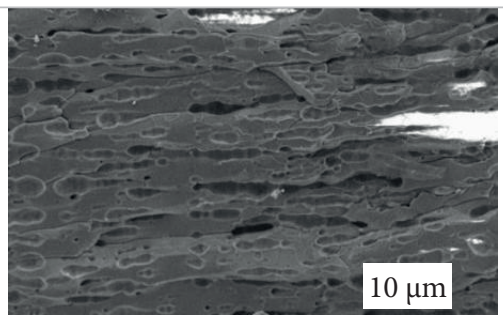

(b)

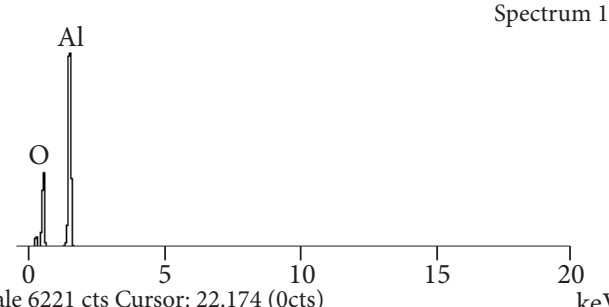

Full scale 6221 cts Cursor: 22.174 (0cts) $\mathrm{keV}$

Figure 13. View of the cross section of the material. (a) SEM with magnitude of 1,000X; (b) Spectrum of EDX in this section: $19.23 \% \mathrm{C}, 44.36 \% \mathrm{O}_{2}$ and $36.41 \% \mathrm{Al}$.
Figure 13 shows images taken from the SEM performed at the edge of the deposited coating. In such a way, the effect of ablation at the nozzle throat was not observed due to the formation of the condensed material. The condensed material exhibits a laminar and fuzzy deposited pattern, as can be seen in Fig. 13a. The deposit coating was analyzed by EDS, according to Fig. 13b, where the presence of aluminum was mainly detected, which is the main component of the propellant. Carbon was also found due to the residues of the firing test. It was also observed, after the firing test, that the condensed aluminum oxide formed at the graphite nozzle insert decreased the nozzle throat area.

In order to identify the chemical species present in the structure of the coating material deposited over the rocket nozzle surface, XRD analysis was conducted. The sample was ground and analyzed in the form of a powder. The results are shown in Fig. 14. It can be seen from the XRD analysis (Fig. 14) that the coating material removed from the nozzle essentially consists of aluminum oxide.

The coordinate (MMC) measurements were done using a $\mathrm{CNC}$ Zeis Accura. The erosion that occurs in the diameter of the insert was evaluated. The regions investigated were the internal diameter of the converging entrance, where the exit of gases occurs during firing, and the inner diameter from the exit cone. The evaluation was done by setting a $z$ axis across the center of the insert, considering a pitch distance of $2 \mathrm{~mm}$. Thirty-two measurements throughout the diameter were performed at the exit cone divergent surface region and another 26 measurements, at the convergent surface. It can be seen from Fig. 15 that the measurements were largely unchanged. Then, no ablation effect was observed in the graphite insert. This fact is attributed to the formation of the coating material over the surface of the rocket nozzle, as can be seen in Fig. 11.

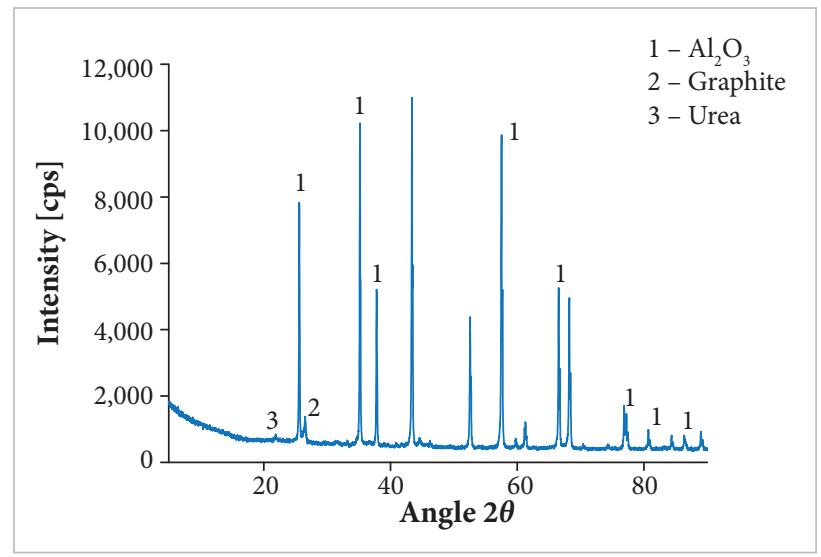

Figure 14. Diffractogram of the coating material removed from the nozzle. 


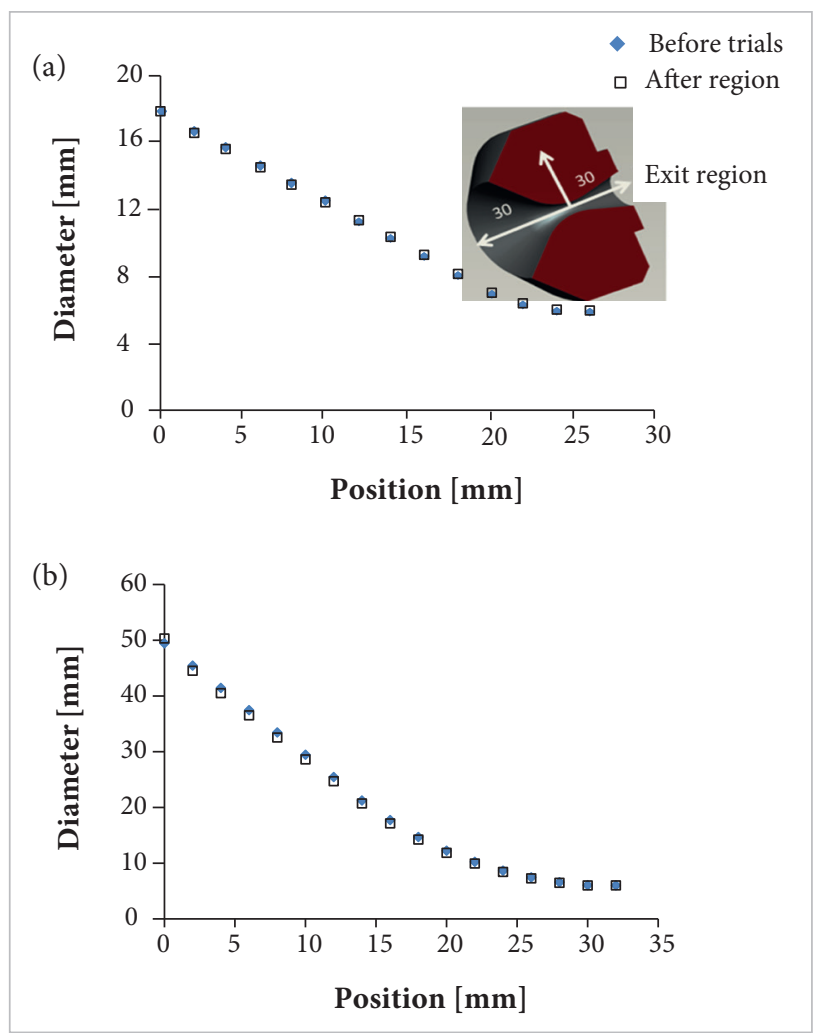

Figure 15. Measurements of the cross section diameter of the convergent and divergent sections from the rocket nozzle. (a) Entrance region; (b) Exit region.

\section{CONCLUSIONS}

A new SRM test was designed, based on a similar device described in the literature, to evaluate the ablation, thrust and the thermal protection system. The results of thrust as a function of firing time, which is the main performance parameter of the SRM, are constant and independent of the throat diameter.

The firing test of the SRM showed that the measured thrust was similar to the results calculated theoretically. This suggests that the formation of the coating may happen during the firing test continuously, i.e. there was no effect on the erosion of the nozzle. The coating deposited in the nozzle area consists basically on aluminum oxide, which is due to the aluminum from propellant formulation.

The formation of deposit in the throat and conical exit of the insert prevented evaluating the effect ablation of the insert material. Therefore, investigations will be done on the phenomena involved in the formation of the anomalous coating materials to overcome SRM malfunction. These studies involve a detailed analysis of the propellant formulation, conducting further tests to evaluate if the deposit coating is eliminated.

\section{ACKNOWLEDGEMENTS}

The authors are grateful to the Space Systems Division (ASE), Chemical Division (AQI), Space Propulsion Division (APE), Mechanical Division (AME), Materials Division (AMR) and Integration and Test Division (AIE) of the Instituto de Aeronáutica e Espaço (IAE) and the CENIC Company for cooperation and technical assistance in the preparation and execution of this research.

\section{AUTHOR'S CONTRIBUTION}

Reis RI did the design of the SRM, write the paper, the experiments and discuss results. Shimote WK also designs the SRM testing device and writes the paper and discuss the results. Pardini LC did the experiments, writing also and discusses the results. All authors conceived the idea, wrote the main text and performed the experiments.

\section{REFERENCES}

CETPC 273 (1994) Revision 2.0. Thermochemical Equilibrium Calculation Software.

Cortopassi AC, Boyer E, Kenneth KK (2009) Update: a subscale solid rocket motor for characterization of submerged nozzle erosion. Proceedings of the 45th AIAA/ASME/SAE/ASEE Joint Propulsion Conference and Exhibit; Denver, USA.
Davenas A (1993) Solid rocket propulsion technology. Oxford; New York: Pergamon Press.

Delaney LJ, Eagleton LC, Jones WH (1964) A semi-quantitative prediction of the erosion of graphite nozzle inserts. Proceedings of the Solid Propellant Rocket Conference; Palo Alto, USA.

Geisler R, Beckman C (1982) Ballistic anomaly trends in subscale 
solid rocket motors. Proceedings of the 18th AIAA/ASME/SAE/ASEE Joint Propulsion Conference and Exhibit; Cleveland, USA.

Geisler R, Beckman C (1998) The history of the BATES motors at the Air Force Rocket Propulsion Laboratory. Proceedings of the 34th AIAA/ASME/SAE/ASEE Joint Propulsion Conference and Exhibit; Cleveland, USA.

Glotov OG (2006) Condensed combustion products of aluminized propellants. IV. Effect of the nature of nitramines on aluminum agglomeration and combustion efficiency. Combust Explo Shock+ 42(4):436-449. doi: 10.1007/s10573-006-0073-z

Kubota N (2007) Propellants and explosives: thermochemical aspects of combustion. 2nd edition. Weinheim: Wiley-VCH Verlag.

Najjar FM, Massa L, Fiedler R, Haselbacher A, Wasistho B, Balachandar S (2005) Effects of aluminum propellant loading and size distribution in BATES motors: a multiphysics computational analysis. Proceedings of the 41th AIAA/ASME/SAE/ASEE Joint Propulsion Conference and Exhibit; Tucson, USA.

Sciamareli J, Takahashi MFK, Teixeira JM, Iha K (2002) Propelente sólido compósito polibutadiênico: 1 - influência do agente de ligação. Quím Nova 25(1):107-110. doi: 10.1590/S010040422002000100018
Susuki S, Chiba M (1989) Combustion efficiency of aluminized propellant. Proceedings of the 25th AIAA/ASME/SAE/ASEE Joint Propulsion Conference and Exhibit; Monterey, USA.

Sutton GP (1986) Rocket propulsion elements: an introduction to the engineering of rockets. 5th edition. New York: Wiley.

Thakre P, Yang V (2007) Graphite nozzle material erosion in solid propellant rocket motors. Proceedings of the 45th AIAA Aerospace Sciences Meeting and Exhibit; Reno, USA.

Wani V, Mehihal M, Jain S, Singh PP, Bhattacharya B (2012) Studies on the influence of testing parameters on dynamic and transient properties of composite solid rocket propellants using a dynamic mechanical analyzer. J Aerosp Technol Manag 4(4):443-452. doi: 10.5028/jatm.2012.04044012

Wermimont EJ (1993) 48-inch subscale motor material testing of Space Shuttle advanced solid rocket motor nozzle carbon cloth phenolic ablatives. Proceedings of the 29th AIAA/ASME/SAE/ASEE Joint Propulsion Conference and Exhibit; Monterey, USA.

Zucrow MJ, Hoffman JD (1976) Gas dynamics. Vol. I. New York: Wiley. 